\title{
Early objective response to avelumab treatment is associated with improved overall survival in patients with metastatic Merkel cell carcinoma
}

\author{
Sandra P. D'Angelo ${ }^{1}$ Matthias Hunger ${ }^{2}$. Andrew S. Brohl ${ }^{3}$. Paul Nghiem ${ }^{4}$. Shailender Bhatia ${ }^{5} \cdot$ Omid Hamid $^{6}$. \\ Janice M. Mehnert ${ }^{7} \cdot$ Patrick Terheyden $^{8} \cdot$ Kent C. Shih $^{9} \cdot$ Isaac Brownell ${ }^{10} \cdot$ Céleste Lebbé $^{11} \cdot$ Karl D. Lewis $^{12}$. \\ Gerald P. Linette ${ }^{13} \cdot$ Michele Milella $^{14} \cdot$ Michael Schlichting $^{15} \cdot$ Meliessa H. Hennessy $^{16} \cdot$ Murtuza Bharmal $^{15}$
}

Received: 28 August 2018 / Accepted: 24 December 2018 / Published online: 5 February 2019

(c) The Author(s) 2019

\begin{abstract}
Background Response rates are primary endpoints in many oncology trials; however, correlation with overall survival (OS) is not uniform across cancer types, treatments, or lines of therapy. This study explored the association between objective response (OR) and OS in patients with chemotherapy-refractory metastatic Merkel cell carcinoma who received avelumab (anti-PD-L1).

Methods Eighty-eight patients enrolled in JAVELIN Merkel 200 (part A; NCT02155647) received i.v. avelumab 10 mg/kg every 2 weeks until confirmed progression, unacceptable toxicity, or withdrawal. Using conditional landmark analyses, we compared OS in patients with and without confirmed OR (RECIST v1.1). We applied a Cox model that included OR as a time-varying covariate and adjusted for age, visceral disease, and number of previous therapies.

Results Twenty-nine patients had confirmed OR; 20 by study week 7 and 7 more between study weeks 7 and 13. Survival probabilities 18 months after treatment initiation were 90\% [95\% confidence interval (CI) 65.6-97.4] in patients with OR at week 7 and 26.2\% (95\% CI 15.7-37.8) in patients without OR but who were alive at week 7. Median OS was not reached in patients with OR and was 8.8 months (95\% CI 6.4-12.9) in patients without. Similar results were observed for the week 13 landmark. The adjusted Cox model showed OR was associated with a 95\% risk reduction of death [hazard ratio $0.052(95 \%$ CI 0.018-0.152)] compared with a nonresponse.

Conclusions Patients with OR by 7 or 13 weeks had significantly longer OS than patients without, confirming that early OR is an endpoint of major importance.
\end{abstract}

Keywords Merkel cell carcinoma Avelumab $\cdot$ PD-L1 · Objective response · Overall survival $\cdot$ Endpoint validation

$\begin{array}{ll}\text { Abbreviations } \\ \text { CI } & \text { Confidence interval } \\ \text { CR } & \text { Complete response } \\ \text { ECOG PS } & \begin{array}{l}\text { Eastern Cooperative Oncology Group perfor- } \\ \text { mance status }\end{array} \\ \text { FDA } & \begin{array}{l}\text { Food and drug administration } \\ \text { HR }\end{array} \\ & \text { Hazard ratio }\end{array}$

The work has been previously presented as an abstract and poster at the 2018 American Society of Clinical Oncology-Society for Immunotherapy of Cancer (ASCO-SITC) Clinical ImmunoOncology Symposium, January 25-27, 2018, San Francisco, California, USA [1].

Sandra P. D’Angelo

dangelos@mskcc.org

Extended author information available on the last page of the article

$\begin{array}{ll}\text { IERC } & \text { Independent endpoint review committee } \\ \text { irRC } & \text { Immune-related response criteria } \\ \text { KM } & \text { Kaplan-Meier } \\ \text { mMCC } & \text { Metastatic Merkel cell carcinoma } \\ \text { NSCLC } & \text { Non-small cell lung cancer } \\ \text { OR } & \text { Objective response } \\ \text { ORR } & \text { Objective response rate } \\ \text { OS } & \text { Overall survival } \\ \text { PR } & \text { Partial response } \\ \text { RCC } & \text { Renal cell carcinoma }\end{array}$




\section{Introduction}

Merkel cell carcinoma (MCC) is a rare and aggressive neuroendocrine carcinoma of the skin [2-5]. Historically, survival rates in patients with MCC are poor, with an estimated mortality rate between 33 and 46\% [6]. Metastatic MCC (mMCC) develops in approximately one-fifth of patients who present with local or regional disease [7].

Historically, the only treatment option in patients with mMCC was chemotherapy with a platinum agent. Despite the objective response rates (ORR) to chemotherapy as a first-line therapy for mMCC being relatively high, 52-61\%, these responses were short-lived, with the median duration of response with first-line chemotherapy being approximately 3 months [8]. Although patients had objective responses (ORs) with chemotherapy, these responses did not translate into an overall survival (OS) benefit $[6,8-11]$. In one study in patients presenting with mMCC, the 2-year survival rate was $11 \%$ [7].

Avelumab (MSB0010718C) is a fully human anti-PDL1 IgG1 monoclonal antibody that inhibits interactions between PD-L1 and PD-1 but leaves intact the PD-L2/ PD-1 pathway [12]. It is the first drug approved for the treatment of mMCC in a number of countries, including the United States and Japan, and the European Union. The approvals were based on data from the open-label, single-arm, multicenter clinical trial JAVELIN Merkel 200, which demonstrated a clinically meaningful and durable ORR [13, 14].

OS is considered the most reliable and clinically meaningful endpoint for evaluating drug efficacy in oncology clinical trials $[15,16]$. However, evaluating OS requires large sample sizes and prolonged follow-up and can be confounded by postprogression therapies [17]. Thus, alternative endpoints, such as ORR and durable ORR, are being used as the primary endpoint in many oncology trials, yet these response rates have not been shown to correlate with OS across cancer types, treatments, or lines of therapy $[17,18]$.

Immunotherapy has been shown to improve OS compared with chemotherapy in various advanced cancer types, including melanoma and non-small cell lung cancer (NSCLC) [19, 20]. In particular, long-term clinical trial data show that a number of patients treated with checkpoint inhibitors experience a durable anti-tumor response [21], suggesting that the way patients' disease responds to these treatments is different from their response to chemotherapy [22].

Previous studies in advanced NSCLC and renal cell carcinoma (RCC) have shown that in patients treated with anti-PD-1/PD-L1 antibodies, OR is associated with higher OS rates [22, 23]. In a recent meta-analysis of individual-patient-level data from 13 randomized immunotherapy trials of anti-PD-1/PD-L1 agents submitted to the US Food and Drug Administration (FDA), it was observed that patients with an OR had longer survival than patients whose disease did not respond [24].

Better understanding the relationship between OR and OS in patients treated with immunotherapy will help clinicians and decision makers assess therapeutic efficacy and potential for long-term clinical benefit.

The objective of this study is to investigate the association between OR and OS in patients with $\mathrm{mMCC}$ who were treated with avelumab.

\section{Materials and methods}

\section{Study design}

Data were analyzed from part A of trial EMR 100070-003/ NCT02155647/JAVELIN Merkel 200, a single-arm, openlabel, multicenter phase II study of avelumab as secondline or later therapy in patients with distant mMCC. Patients must have received $\geq 1$ line of chemotherapy for the treatment of mMCC and had disease progression on or after the most recent line of chemotherapy. Eligible patients had an Eastern Cooperative Oncology Group performance status (ECOG PS) of 0 or 1 at trial entry, an estimated life expectancy of $>12$ weeks, $\geq 1$ unidimensional measurable lesion by RECIST v1.1, and adequate hematologic, hepatic, and renal function. Further study design details have been published previously [14].

Patients received avelumab at a dose of $10 \mathrm{mg} / \mathrm{kg}$ as a $1-\mathrm{h}$ intravenous infusion every 2 weeks until confirmed disease progression, unacceptable toxicity, or occurrence of any other criterion for withdrawal. The date of data cutoff for the analyses was March 24, 2017, at which point all patients had $\geq 18$ months of follow-up from the date of the last patient enrolled. Tumor assessment was performed every 6 weeks, and the radiological images by computed tomography or MRI and photographs of skin lesions were reviewed by an independent endpoint review committee (IERC) to determine response according to RECIST $v 1.1$ [25].

OR [defined as either partial response (PR) or complete response (CR)] required confirmation of response per RECIST by IERC, preferably at the next regularly scheduled 6-week assessment and no sooner than 5 weeks.

\section{Statistical analyses}

Comparative time-to-event analyses using time-dependent variables, such as tumor response, as predictors are different from analyses using baseline characteristics, which are fixed before the occurrence of any outcome event. This is 
because the covariate of interest ("response") is changing with time: Patients whose disease responds to treatment must have at least survived from the time of treatment initiation to the time of response, whereas there is no such requirement for patients whose disease does not respond. To account for this "time-to-response" or "immortal time" bias, two approaches were used: the landmark analysis approach and extended Cox regression models with a timevarying covariate $[26,27]$.

In the landmark approach, a fixed time after the start of therapy is chosen as a landmark for analyzing survival by response. Only patients alive at the landmark are then included in the analysis and separated into two categories, distinguished by whether they experienced an OR up to that time. Consequently, the landmark method ignores all new ORs after the landmark and ignores all deaths before that time. OS is then analyzed conditional on the response status at the landmark time of patients who survived up to that time [27].

Two different landmarks were chosen: The first landmark was at week 7 , covering responses experienced up to the first tumor assessment; the second landmark was at week 13 and covered responses that occurred between the first and second tumor response assessments. Survival probabilities in the two groups conditional on the response of patients at week 7 or week 13 were illustrated using Kaplan-Meier (KM) curves, and median OS was calculated in the two groups.

In contrast to the landmark method, the Cox regression model makes use of all patient data and does not ignore responses after a specific point in time [27]. The timevarying response variable included in the extended Cox regression model tracks whether the classifying event ("response") has occurred during the estimation process. All patients would be classified initially as patients with nonresponse. Patients whose disease responded to treatment during follow-up would be switched into the responder group at the time that the response occurred and remain in that group until death. Different Cox regression models were applied. The first model included the timevarying covariate "response" as the only covariate. The second model additionally included age at baseline (continuous), the presence of visceral metastases (yes vs no) at baseline, and the number of previous therapies in the metastatic setting ( 1 vs $>1)$ as covariates. A third model additionally adjusted for PD-L1 expression, tumor Merkel cell polyomavirus status, ECOG PS, and tumor burden at baseline. Selection of these variables was based on clinical input, and these variables have been shown to be predictors of OS in patients with metastatic skin cancer [28].

Statistical analyses were performed using SAS v9.4 (SAS Institute, Inc; Cary, NC, USA).

\section{Results}

\section{Patient population}

In the 88 patients who received $\geq 1$ dose of avelumab, median time since diagnosis of metastatic disease was 10.4 months (range 1.5-159.0 months; Table 1). Forty one percent of the patients had received $\geq 2$ prior lines of chemotherapy, indicating a heavily pretreated population with advanced metastatic disease. The primary tumor site in most patients was skin. Confirmed ORs to avelumab were achieved in 29 patients [33.0\%; $95 \%$ confidence interval (CI) $23.3-43.8 \%$ ), 19 of whom had PR. Of the 29 patients with a confirmed response, 26 patients (KM estimate, 93\%; 95\% CI 75-98\%) had a durable response of $\geq 6$ months and 18 patients (KM estimate, $71 \%$; 95\% CI $51-85 \%$ ) had a duration of response $\geq 12$ months.

The proportion of patients who were progression free at 18 months was $29.0 \%$ (95\% CI 19-39\%). The estimated OS rate at 18 months was $40 \%$ (95\% CI 29-50\%) [29]. Nineteen patients (22\%) received subsequent anticancer drug therapy.

\section{Landmark approach}

Twenty patients were included in the group with response at week 7; 16 had a PR and 4 had CR prior to week 7. Five patients died, and 1 patient withdrew consent before week 7; these patients, all without OR, were not included in the week 7 landmark analysis. Twenty-seven patients were included in the response group at week 13; 22 had a PR and 5 had CR prior to week 13. Eleven patients died, and 2 patients withdrew consent before week 13; these patients, all without OR, were not included in the week 13 landmark analysis.

The KM curve for OS by tumor response at the week 7 landmark is shown in Fig. 1. Compared with the median OS of 8.8 months (95\% CI 6.4-12.9 months) at week 7 in the group without response, the median OS at week 7 in the group with response was not reached. In the group without response at week 7 , survival probabilities at 6,12 , and 18 months after treatment initiation (conditional on surviving week 7) were $65.5 \%, 40.1 \%$, and $26.2 \%$, respectively (Table 2). In the week 7 response group, survival probabilities at 6,12 , and 18 months after treatment initiation (conditional on surviving week 7) were $100 \%, 95.0 \%$, and $90.0 \%$, respectively (Table 2).

The KM curve for OS by tumor response at the week 13 landmark is shown in Fig. 2. Compared with the median OS of 8.7 months (95\% CI 6.4-11.6 months) in patients without response at week 13 , median OS in patients with 
Table 1 Patient characteristics

\begin{tabular}{|c|c|}
\hline Baseline characteristics & Patients $(N=88)$ \\
\hline Median age (range), years & $72.5(33-88)$ \\
\hline Age $<65$ years, $n(\%)$ & $22(25)$ \\
\hline Age $\geq 65$ years, $n(\%)$ & $66(75)$ \\
\hline \multicolumn{2}{|l|}{ Sex, $n(\%)$} \\
\hline Male & $65(74)$ \\
\hline Female & $23(26)$ \\
\hline \multicolumn{2}{|l|}{ Site of primary tumor, $n(\%)$} \\
\hline Skin & $67(76)$ \\
\hline Lymph node & $12(14)$ \\
\hline Other & $2(2)$ \\
\hline Missing & $7(8)$ \\
\hline \multicolumn{2}{|l|}{ Visceral disease at study entry, $n(\%)$} \\
\hline Present & $47(53)$ \\
\hline Absent & $41(47)$ \\
\hline \multicolumn{2}{|l|}{ ECOG PS, $n(\%)$} \\
\hline 0 & $49(56)$ \\
\hline 1 & $39(44)$ \\
\hline \multicolumn{2}{|l|}{ Merkel cell polyomavirus, $n(\%)$} \\
\hline Positive & $46(52)$ \\
\hline Negative & $31(35)$ \\
\hline Not evaluable & $11(13)$ \\
\hline \multicolumn{2}{|l|}{ PD-L1 expression status, $n(\%)$} \\
\hline Positive & $58(66)$ \\
\hline Negative & $16(18)$ \\
\hline Not evaluable & $14(16)$ \\
\hline Median sum of target lesion diameters at baseline per IERC (range), $\mathrm{mm}$ & $79.0(16-404)[N=77]$ \\
\hline Median time since first diagnosis (range), months & $19.8(2.9-159.0)$ \\
\hline Median time since first diagnosis of metastatic disease (range), months & $10.4(1.5-159.0)$ \\
\hline \multicolumn{2}{|l|}{ Previous systemic anticancer treatments, $n(\%)$} \\
\hline 1 & $52(59)$ \\
\hline 2 & $26(30)$ \\
\hline 3 & $7(8)$ \\
\hline$\geq 4$ & $3(3)$ \\
\hline \multicolumn{2}{|l|}{ Follow-up and efficacy outcomes } \\
\hline Median follow-up (range), months & $23.0(18.7-32.0)$ \\
\hline Progression-free survival rate at 18 months $(95 \% \mathrm{CI}), \%$ & $29(19-39)$ \\
\hline OS rate at 18 months $(95 \% \mathrm{CI}), \%$ & $40(29-50)$ \\
\hline \multicolumn{2}{|l|}{ Confirmed best overall response, $n(\%)$} \\
\hline $\mathrm{CR}$ & $10(11)$ \\
\hline PR & $19(22)$ \\
\hline Stable disease & $9(10)$ \\
\hline Progressive disease & $32(36)$ \\
\hline Nonevaluable & $18(20)$ \\
\hline Objective response rate $(\mathrm{CR}+\mathrm{PR})(95.9 \% \mathrm{CI}), \%^{\mathrm{a}}$ & $33.0(23.3-43.8)$ \\
\hline
\end{tabular}

$C I$ confidence interval, $C R$ complete response, ECOG PS Eastern Cooperative Oncology Group performance status, IERC Independent Endpoint Review Committee, $O S$ overall survival, $P R$ partial response

${ }^{a}$ Exact confidence interval using the Clopper-Pearson method 
Fig. $1 \mathrm{KM}$ curve for OS by OR at the week 7 landmark

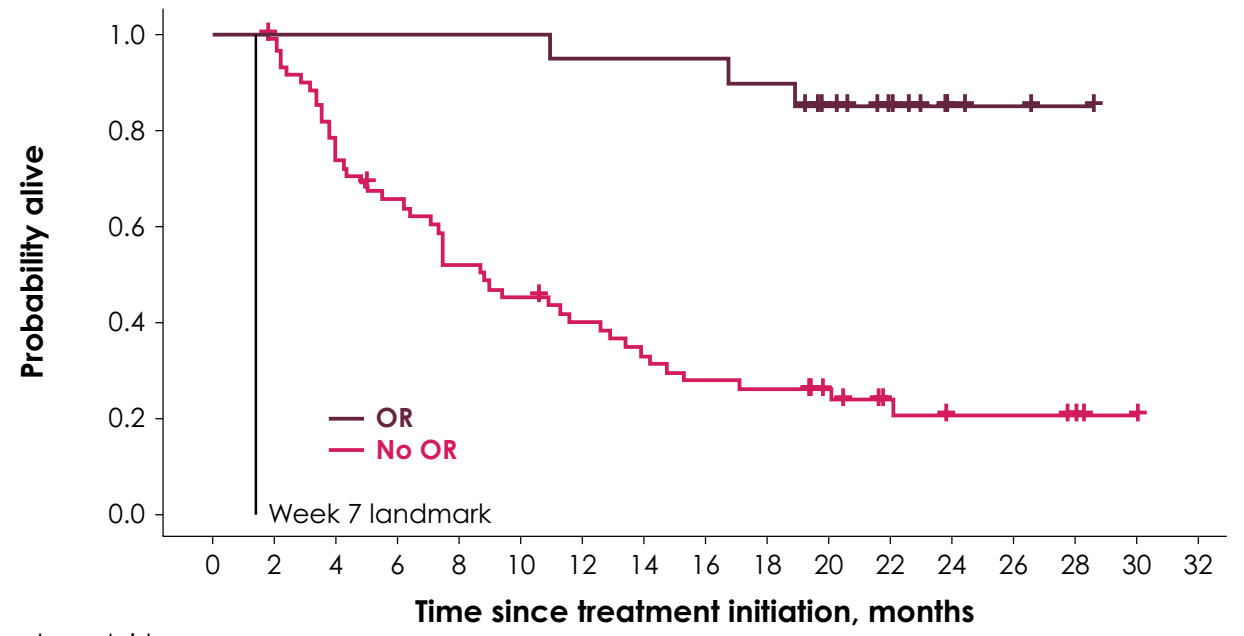

Number at risk

$\begin{array}{llllllllllllllllll}\text { OR } & 20 & 20 & 20 & 20 & 20 & 20 & 19 & 19 & 19 & 18 & 12 & 8 & 3 & 2 & 1 & 0 & 0 \\ \text { No } & 62 & 61 & 48 & 39 & 31 & 27 & 23 & 19 & 16 & 15 & 11 & 7 & 5 & 5 & 4 & 1 & 0\end{array}$

Table 2 Survival probabilities in response group and nonresponse group (conditional on surviving week 7 and week 13 landmarks)

Fig. 2 KM curve for OS by OR at the week 13 landmark

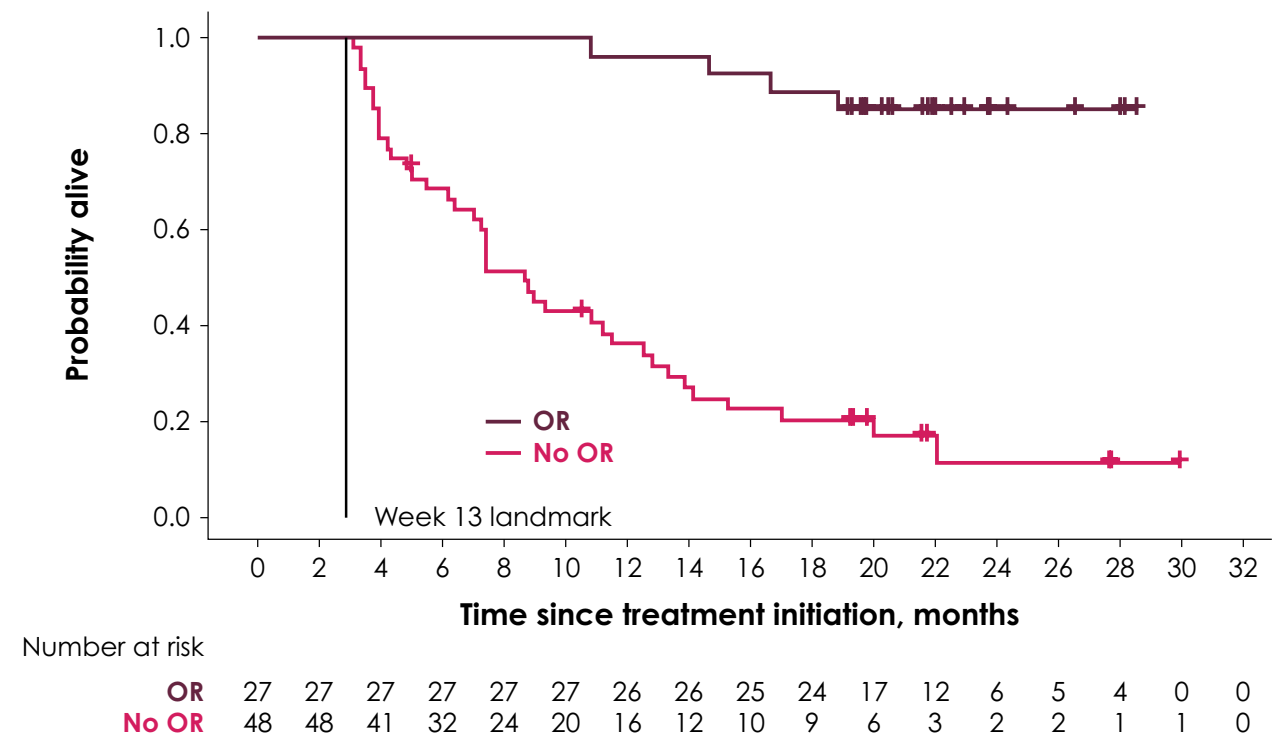

Number at risk

\begin{tabular}{|c|c|c|c|c|}
\hline \multirow{2}{*}{$\begin{array}{l}\text { Posttreatment initia- } \\
\text { tion follow-up period }\end{array}$} & \multicolumn{2}{|l|}{ Week 7 landmark } & \multicolumn{2}{|l|}{ Week 13 landmark } \\
\hline & $\begin{array}{l}\text { Patients with } \\
\text { response } \\
(95 \% \mathrm{CI}), \%\end{array}$ & $\begin{array}{l}\text { Patients without } \\
\text { response } \\
(95 \% \text { CI }), \%\end{array}$ & $\begin{array}{l}\text { Patients with } \\
\text { response } \\
(95 \% \mathrm{CI}), \%\end{array}$ & $\begin{array}{l}\text { Patients without } \\
\text { response } \\
(95 \% \text { CI }), \%\end{array}$ \\
\hline 5 months & $100(100-100)$ & $65.5(52.1-76.0)$ & $100.0(100-100)$ & $68.6(53.4-79.8)$ \\
\hline 12 months & $95.0(69.5-99.3)$ & $40.1(27.7-52.2)$ & $96.3(76.5-99.5)$ & $36.1(22.7-49.7)$ \\
\hline 18 months & $90.0(65.6-97.4)$ & $26.2(15.7-37.8)$ & $88.9(69.4-96.3)$ & $20.3(10.1-33.0)$ \\
\hline
\end{tabular}

CI confidence interval

response at week 13 was not reached. In general, there was a high similarity of estimated survival probabilities between the week 7 and week 13 landmark analyses, as reported in Table 2. Compared with the week 7 landmark analyses, conditional survival probabilities based on the week 13 landmark were slightly higher in the response group and slightly lower in the group without response at months 12 and 18 . 
Four patients had a CR before the week 7 landmark, of whom three were still alive at the date of data cutoff. One additional patient had a CR between the week 7 and week 13 landmarks but died at month 19.

\section{Cox regression model}

In the unadjusted Cox regression model, any OR had a hazard ratio (HR) of 0.064 (95\% CI 0.022-0.181), ie, an OR was associated with a $94 \%$ risk reduction of death, compared with nonresponse (Table 3). In the model adjusting for age, visceral metastases, and number of previous therapies, OR had a HR of 0.052 (95\% CI 0.018-0.152) (Table 3). The HR for the presence of visceral metastases at baseline was 1.995 (95\% CI 1.102-3.613), indicating that patients with visceral metastases had nearly twice the risk of death compared with patients without visceral disease. The association between OR and OS did not change when analyses were further adjusted for PD-L1 expression, Merkel cell polyomavirus status, ECOG PS, and tumor burden at baseline (results not shown).

\section{Discussion}

Clinical data from the JAVELIN Merkel 200 trial were used to investigate the association between tumor response and OS in patients with mMCC treated with avelumab. This is the first time the two outcomes have been tested for association in this indication, and results show that early OR (the majority of responses were PR and occurred by week 7) is a clinically relevant predictor of OS in patients with $\mathrm{mMCC}$ treated with second-line or later avelumab. This is important when placed into context of chemotherapy in mMCC, whereby responses can be very high, yet durability is dismal without an association with survival.

Results of the landmark analyses reveal considerably higher survival probabilities at 6, 12, and 18 months in patients with OR than in patients without a response. Having a response early, either at week 7 or week 13, is predictive of improved OS: $90 \%$ of these patients were still alive 18 months after treatment initiation, compared with 20-26\% of patients without response at week 7 and 13 . In addition, results from the Cox regression model showed that the association between OR (early or late) and OS remained stable when adjusted for patient characteristics that may impact survival; among those, only visceral metastases present at study baseline were associated with increased mortality.

Of the 48 patients without response at the week 13 landmark, 7 were still alive at the date of data cutoff (Fig. 2). Two of them had a late response after 18 and 36 months, respectively. The remaining 5 patients had good prognostic factors in that they all had no visceral disease at baseline and an ECOG PS of 0 as well as lower tumor burden at baseline, on average.

Increasing clinical experience indicates that traditional response criteria may not be sufficient to fully characterize response to immunotherapies [30, 31]. For example, mechanisms of action of immune-modulating agents are associated with delayed responses and flares in tumors associated with the influx of immune cells [32]. On these grounds, a tumor assessment system has been developed that incorporates these delayed or flare-type responses and designated immune-related response criteria (irRC) [33]. To supplement standard RECIST v1.1 evaluations, additional evaluations using modified irRC have been performed in this trial, combining the concepts of the irRC with RECIST v1.1. For modified irRC, only target and measurable lesions were considered, and ORRs in this trial were similar if modified irRC were used instead [14]. However, given the absence of definite modified criteria to be used in conjunction with immunotherapy, RECIST v1.1 continues to be used as the standard method to assess response to immunotherapy in clinical practice.

The strong association between OR and OS in patients with mMCC who are treated with second-line or later avelumab is important to clinical practice, in which this association could be used to make survival predictions earlier in a
Table 3 Regression output from Cox regression model with response as time-varying covariate

\begin{tabular}{llllr}
\hline Parameter & $\begin{array}{l}\text { Hazard ratio } \\
\text { Estimate }\end{array}$ & $\begin{array}{l}\text { Lower limit } \\
95 \% \text { CI }\end{array}$ & $\begin{array}{l}\text { Upper limit } \\
95 \% \text { CI }\end{array}$ \\
\hline Unadjusted model & & & & \\
$\quad$ Response: OR vs no OR & 0.064 & 0.022 & 0.181 & $<0.0001$ \\
Adjusted model & & & & $<0.0001$ \\
Response: OR vs no OR & 0.052 & 0.018 & 0.152 & 0.3941 \\
Age (per year) & 1.011 & 0.986 & 1.036 & 0.0226 \\
$\quad$ Visceral metastases at baseline: yes vs no & 1.995 & 1.102 & 3.613 & 0.8981 \\
Number of prior therapies: $>1$ vs 1 & 1.037 & 0.596 & 1.802 & \\
\hline
\end{tabular}

$C I$ confidence interval, $O R$ objective response 
patient's treatment. This is in contrast with chemotherapy, whereby responses can be very high; however, they are not durable, without association with survival. On the basis of these findings, physicians may be able to reassure patients whose disease demonstrates early response to avelumab that they may have an improved prognosis in terms of expected duration of survival. The observed ORR and corresponding survival probabilities with second-line or later avelumab represents a therapeutic improvement compared with historical results with chemotherapy-including first-line treatment, which rarely produces durable response lasting 6 months in mMCC and is associated with a low 2-year survival rate [8]. Interestingly, within the same disease, two mechanisms of action can result in profoundly different associations between OR and OS. Whereas in patients treated with avelumab, an OR is predictive of improved OS, this is not the case for cytotoxic chemotherapy, the prior standard of care: Although $>50 \%$ of patients have a robust initial response to first-line chemotherapy at $2-3$ months, $95 \%$ of patients will have had disease progression by 15 months, with very little effect of whether there was response at 2-3 months [8].

The predictive and prognostic value of baseline $\mathrm{CD}$ positivity at the invasive tumor margin has been evaluated in part A of JAVELIN Merkel 200, and a nonsignificant trend toward higher response rate and longer OS with higher tumor $\mathrm{CD}^{+}$levels was observed, but given the small sample, the presence of tumor responses across all evaluated subgroups cannot be described as predictive or prognostic [34]. Future analysis of $\mathrm{CD} 8^{+}$vs response and survival will continue to be evaluated in first-line avelumab treatment for mMCC.

Previous studies in patients treated with anti-PD-1/PD-L1 antibodies in different tumor types have evaluated the association between tumor response and OS, with results that are consistent with those from JAVELIN Merkel 200. Motzer et al. performed a landmark analysis to examine the correlation between OR and OS in patients with advanced RCC treated with nivolumab [23]. In patients with a response up to the month 4 landmark, OS rates at 12 and 18 months were higher than those in patients with stable or progressive disease [23]. The 18-month OS rate in patients with advanced RCC and OR to nivolumab was $89 \%$. A correlation between response and OS was also reported in the everolimus arm of the trial, although with a smaller magnitude and based on a lower ORR [23]. Similarly, a landmark analysis in patients with advanced NSCLC treated with anti-PD-1/PD-L1 antibodies conducted by Shukuya et al. reported a longer median OS in patients who had a PR between weeks 5-9 than in patients with stable or progressive disease [22]. Mushti et al. recently conducted a meta-analysis using pooled data from 13 active-controlled immunotherapy trials of anti-PD-1/ PD-L1 agents submitted to the FDA between 2014 and 2016 [24]. They found that in the immunotherapy arms, patients with an OR had longer survival than patients without tumor response. Patients with response in the immunotherapy arms also had longer OS than those with response to standard treatment in the active control arms [24]. The 18-month OS rate in patients with OR in the immunotherapy arm was approximately $86 \%$. These data from trials in other diseases treated with anti-PD-1/PD-L1 support the association found in the JAVELIN Merkel 200 study that patients with an OR with avelumab also have longer survival than historical data show with chemotherapy, as demonstrated by the 18 -month OS rate of $90 \%$.

By evaluating individual-patient-level surrogacy between OR and OS, this study addresses one of the criteria for validating surrogate endpoints set out by Buyse et al. [35]. However, a limitation is that trial-level surrogacy, i.e., the association between treatment effects on the two endpoints, cannot be evaluated for avelumab, because this study did not include a randomized active comparator arm and currently there are no data on OR and OS available from other avelumab trials. Additionally, although this study offers the only prospective dataset in this rare disease, the relatively small sample size-88 immune-competent and chemotherapy-refractory patients-may limit the generalizability of results to the $\mathrm{mMCC}$ population regardless of immune status and prior treatment.

Two further limitations to the landmark analysis method should be noted. First, there is a risk of bias stemming from excluding the deaths that occurred prior the week 7 and week 13 landmarks [17]. However, the strong association between OR and OS was confirmed in the Cox regression analysis, which makes use of all data. Second, analyses of surrogate endpoints could lead to inaccurate assumptions about causal relationships with OS. As stated in previous systematic literature reviews, the generalizability of the OR and OS association identified in this study to other treatment types may, therefore, be limited [17].

Finally, OS in patients in this trial may be impacted by subsequent anticancer therapies, and this may also affect the association between OR and OS. Because the majority of patients with response had durable, ongoing responses, subsequent anticancer therapy was less frequent in these patients than in the group without response; among the 21 patients who received subsequent anticancer drug therapy, only 4 were in the avelumab response group.

Clinical trials are ongoing with avelumab in other indications, including gastric/gastro-esophageal junction cancer, head and neck cancer, Hodgkin lymphoma, melanoma, mesothelioma, NSCLC, ovarian cancer, RCC, and urothelial carcinoma. These trials may provide further data to evaluate response to and survival with avelumab therapy.

In conclusion, avelumab therapy had a clinically meaningful impact on survival in patients with previously treated mMCC whose tumors responded by week 7 or week 13 vs those whose tumors did not respond. Early OR to avelumab 
was associated with a clinically meaningful high 18-month OS rate of $90 \%$, likely driven by the sustained durable responses, neither of which were previously reported in the chemotherapy literature for mMCC [14].

Acknowledgements We acknowledge Martha Nicholson (Mapi Group, an ICON plc company, Stockholm, Sweden) for writing assistance. The authors thank the patients and their families and the investigators, co-investigators, and study teams at each of the participating centers, at Merck KGaA, Darmstadt, Germany, and at EMD Serono, Billerica, MA, USA (a business of Merck KGaA, Darmstadt, Germany).

Author contributions SPD, ASB, PN, SB, OH, JMM, PT, KCS, IB, CL, KDL, GPL, MM, and MHH contributed to the collection of study data, interpretation of the findings, and critical review of the manuscript. MB, MH, and MS contributed to conceptualizing the analysis, conducted the analysis, and contributed to interpretation of findings and critical review of the manuscript. All authors read and approved the final manuscript.

Funding This research was funded in part through the National Institute of Health (NIH)/National Cancer Institute (NCI) Cancer Center Support Grant P30 CA015704 (Shailender Bhatia, Paul Nghiem); NIH project number 5K24CA139052 (Paul Nghiem). This trial was funded by Merck KGaA, Darmstadt, Germany, and is part of an alliance between Merck KGaA and Pfizer Inc, New York, NY, USA.

Data Availability The datasets used during and/or analyzed during the current study are available from the corresponding author on reasonable request.

\section{Compliance with ethical standards}

Conflict of interest Sandra P. D'Angelo reports consultancy for EMD Serono, Amgen, Nektar, Immune Design, and GlaxoSmithKline, and reports travel, accommodations, or expenses from Adaptimmune and EMD Serono. Matthias Hunger reports employment by the Mapi Group, which provides consulting for healthcare companies. Andrew S. Brohl reports expert testimony for GlaxoSmithKline by an immediate family member. Paul Nghiem reports consultancy for EMD Serono and Pfizer Inc and reports a patent pending for high-affinity T-cell receptors that target the Merkel polyomavirus, honoraria from EMD Serono and Merck Sharp \& Dohme, and research funding from Bristol-Myers Squibb and EMD Serono. Shailender Bhatia reports consultancy from Genentech/Roche and EMD Serono; travel, accommodations, or expenses from EMD Serono and NantKwest; honoraria from Genentech/Roche, and EMD Serono; and research funding from Bristol-Myers Squibb, Immune Design, Merck, EMD Serono, Conkwest, OncoSec, and NantKwest. Omid Hamid reports consultancy for Amgen, Novartis, Roche, Bristol-Myers Squibb, and Merck; speakers bureau for Bristol-Myers Squibb, Genentech, Novartis, and Amgen; and research funding from AstraZeneca, Bristol-Myers Squibb, Celldex, Genentech, Immunocore, Incyte, Merck, Merck Serono, MedImmune, Novartis, Pfizer, Rinat, and Roche. Janice M. Mehnert reports consultancy for Merck Sharp \& Dohme, Amgen, and Boehringer Ingelheim; travel, accommodations, or expenses from EMD Serono and Merck Sharp \& Dohme; honoraria from Genentech and EMD Serono; research funding from Merck, Sanofi, Novartis, Polynoma, Immunocore, Amgen, AstraZeneca, Incyte, and MacroGenics; and other relationships with Amgen, EMD Serono, Merck, and Boehringer Ingelheim. Patrick Terheyden reports honoraria from Novartis, Roche, and Bristol-Myers Squibb UK; consultancy for Novartis, Roche, BristolMyers Squibb UK, and Merck and Co, Inc; and travel, accommoda- tions, or expenses from Roche and Bristol-Myers Squibb UK. Céleste Lebbé reports honoraria from Roche, Novartis, Amgen, Merck Sharp \& Dohme, and Bristol-Myers Squibb UK; consultancy for Roche, Novartis, Amgen, Merck Sharp \& Dohme, and Bristol-Myers Squibb UK; speakers bureau for Roche, Amgen, Novartis, and Bristol-Myers Squibb UK; research funding from Roche and Bristol-Myers Squibb UK; and travel, accommodations, or expenses from Roche, Amgen, and Bristol-Myers Squibb UK. Karl D. Lewis reports research funding from Merck KGaA, Darmstadt, Germany. Michele Milella reports consultancy for Pfizer and Novartis and travel, accommodations, or expenses from Novartis. Michael Schlichting and Murtuza Bharmal report employment by Merck KGaA, Darmstadt, Germany. Meliessa H. Hennessy reports employment by EMD Serono. All other authors declare that they have no conflict of interest.

Ethical approval and ethical standards Data were analyzed from part A of trial EMR 100070-003/NCT02155647/JAVELIN Merkel 200, a single-arm, open-label, multicenter phase II study of avelumab as second-line or later therapy in patients with distant mMCC. The study was performed in compliance with the Declaration of Helsinki and all current local regulations. Patients were enrolled in accordance with the protocol, which received institutional review board approval at each site. For a list of sites included in the study, please see reference 14 .

Informed consent Written informed consent was provided by patients prior to initiating any study procedures, which covered permission to use their data for any scientific analysis, like this one.

OpenAccess This article is distributed under the terms of the Creative Commons Attribution 4.0 International License (http://creativeco mmons.org/licenses/by/4.0/), which permits unrestricted use, distribution, and reproduction in any medium, provided you give appropriate credit to the original author(s) and the source, provide a link to the Creative Commons license, and indicate if changes were made.

\section{References}

1. D'Angelo SP, Hunger M, Schlichting M, Henessy MG, Bharmal M (2018) Association between objective responses (OR) and overall survival (OS) in patients (pts) with metastatic Merkel cell carcinoma (mMCC) treated with avelumab. J Clin Oncol. https://doi. org/10.1200/JCO.2018.36.5_suppl.193 (Abstract 193)

2. Heath M, Jaimes N, Lemos B, Mostaghimi A, Wang LC, Peñas PF, Nghiem P (2008) Clinical characteristics of Merkel cell carcinoma at diagnosis in 195 patients: the AEIOU features. J Am Acad Dermatol 58:375-381. https://doi.org/10.1016/j.jaad.2007.11.020

3. Paulson KG, Park SY, Vandeven NA, Lachance K, Thomas H, Chapuis AG, Harms KL, Thompson JA, Bhatia S, Stang A, Nghiem $P$ (2018) Merkel cell carcinoma: current US incidence and projected increases based on changing demographics. J Am Acad Dermatol 78:457-463.e2. https://doi.org/10.1016/j.jaad.2017.10.028

4. Youlden DR, Soyer HP, Youl PH, Fritschi L, Baade PD (2014) Incidence and survival for Merkel cell carcinoma in Queensland, Australia, 1993-2010. JAMA Dermatol 150:864-872. https://doi. org/10.1001/jamadermatol.2014.124

5. Becker JC, Stang A, DeCaprio JA, Cerroni L, Lebbé C, Veness M, Nghiem P (2017) Merkel cell carcinoma. Nat Rev Dis Primers 3:17077. https://doi.org/10.1038/nrdp.2017.77

6. Schadendorf D, Lebbé C, zur Hausen A, Avril M-F, Hariharan S, Bharmal M, Becker JC (2017) Merkel cell carcinoma: epidemiology, prognosis, therapy and unmet medical needs. Eur J Cancer 71:53-69. https://doi.org/10.1016/j.ejca.2016.10.022 
7. Allen PJ, Bowne WB, Jaques DP, Brennan MF, Busam K, Coit DG (2005) Merkel cell carcinoma: prognosis and treatment of patients from a single institution. J Clin Oncol 23:2300-2309. https://doi. org/10.1200/JCO.2005.02.329

8. Iyer JG, Blom A, Doumani R, Lewis C, Tarabadkar ES, Anderson A, Ma C, Bestick A, Parvathaneni U, Bhatia S, Nghiem P (2016) Response rates and durability of chemotherapy among 62 patients with metastatic Merkel cell carcinoma. Cancer Med 5:2294-2301. https://doi.org/10.1002/cam4.815

9. Bichakjian CK, Olencki T, Aasi SZ, Alam M, Andersen JS, Blitzblau R, Bowen GM, Contreras CM, Daniels GA, Decker R, Farma JM, Fisher K, Gastman B, Ghosh K, Grekin RC, Grossman K, Ho AL, Lewis KD, Loss M, Lydiatt DD, Messina J, Nehal KS, Nghiem P, Puzanov I, Schmults CD, Shaha AR, Thomas V, Xu YG, Zic JA, Hoffmann KG, Engh AM (2018) Merkel cell carcinoma, version $1.2018, \mathrm{NCCN}$ clinical practice guidelines in oncology. J Natl Compr Cancer Netw 16:742-774. https://doi. org/10.6004/jnccn.2018.0055

10. Tai PT, Yu E, Winquist E, Hammond A, Stitt L, Tonita J, Gilchrist J (2000) Chemotherapy in neuroendocrine/Merkel cell carcinoma of the skin: case series and review of 204 cases. J Clin Oncol 18:2493-2499. https://doi.org/10.1200/JCO.2000.18.12.2493

11. Voog E, Biron P, Martin JP, Blay JY (1999) Chemotherapy for patients with locally advanced or metastatic Merkel cell carcinoma. Cancer 85:2589-2595

12. Heery CR, O'Sullivan Coyne GH, Marte JL, Singh H, Cordes LM, Madan RA, Donahue RN, Grenga I, Lepone L, Neuteboom B, Speit I, Chin KM, Schlom J, Gulley JL (2015) Pharmacokinetic profile and receptor occupancy of avelumab (MSB0010718C), an anti-PD-L1 monoclonal antibody, in a phase I, open-label, dose escalation trial in patients with advanced solid tumors. J Clin Oncol. https://doi.org/10.1200/jco.2015.33.15_suppl.3055 (Abstract 3055)

13. Kaufman H, Russell J, Hamid O, Bhatia S, Terheyden P, D'Angelo SP, Shih KC, Lebbé C, Milella M, Brownell I, Lewis C, Lorch JH, von Heydebreck A, Mahnke L, Nghiem P (2017) Durable responses to avelumab (anti-PD-L1) in patients with Merkel cell carcinoma progressed after chemotherapy: 1-year efficacy update. In: Proceedings of the American Association for Cancer Research Annual Meeting 2017; April 1-5, 2017; Washington, DC. https:// doi.org/10.1158/1538-7445.AM2017-CT079 (Philadelphia (PA): AACR; Cancer Res77(13 Suppl) Abstract nr CT079)

14. Kaufman HL, Russell J, Hamid O, Bhatia S, Terheyden P, D’Angelo SP, Shih KC, Lebbé C, Linette GP, Milella M, Brownell I, Lewis KD, Lorch JH, Chin K, Mahnke L, von Heydebreck A, Cuillerot JM, Nghiem P (2016) Avelumab in patients with chemotherapy-refractory metastatic Merkel cell carcinoma: a multicentre, single-group, open-label, phase 2 trial. Lancet Oncol 17:1374-1385. https://doi.org/10.1016/S1470-2045(16)30364-3

15. Blumenthal GM, Karuri SW, Zhang H, Zhang L, Khozin S, Kazandjian D, Tang S, Sridhara R, Keegan P, Pazdur R (2015) Overall response rate, progression-free survival, and overall survival with targeted and standard therapies in advanced non-smallcell lung cancer: US Food and Drug Administration trial-level and patient-level analyses. J Clin Oncol 33:1008-1014. https://doi. org/10.1200/jco.2014.59.0489

16. Zhao F (2016) Surrogate end points and their validation in oncology clinical trials. J Clin Oncol 34:1436-1437. https://doi. org/10.1200/jco.2016.66.4581

17. Kiba T (2011) The choice of the endpoint to assess the efficacy or effectiveness in advanced or metastatic cancer tumors. J Cancer Sci Ther 3:154-157. https://doi.org/10.4172/1948-5956.1000079

18. Jain RK, Lee JJ, Ng C, Hong D, Gong J, Naing A, Wheler J, Kurzrock R (2012) Change in tumor size by RECIST correlates linearly with overall survival in phase I oncology studies. J Clin Oncol 30:2684-2690. https://doi.org/10.1200/jco.2011.36.4752
19. Robert C, Thomas L, Bondarenko I, O'Day S, Weber J, Garbe C, Lebbé C, Baurain JF, Testori A, Grob JJ, Davidson N, Richards J, Maio M, Hauschild A, Miller WH Jr, Gascon P, Lotem M, Harmankaya K, Ibrahim R, Francis S, Chen TT, Humphrey R, Hoos A, Wolchok JD (2011) Ipilimumab plus dacarbazine for previously untreated metastatic melanoma. N Engl J Med 364:25172526. https://doi.org/10.1056/NEJMoa1104621

20. Brahmer JR, Rodríguez-Abreu D, Robinson AG, Hui R, Csôszi T, Fülöp A, Gottfried M, Peled N, Tafreshi A, Cuffe S, O'Brien M, Rao S, Hotta K, Riccio A, Yang J, Pietanza MC, Reck M (2017) Updated analysis of KEYNOTE-024: pembrolizumab vs platinum-based chemotherapy for advanced NSCLC with PD-L1 TPS $\geq 50 \%$. In: Abstracts from the IASLC 18th World Conference on Lung Cancer; October 15-18, 2017; Yokohama, Japan. https://doi.org/10.1016/j.jtho.2017.09.431 (J Thorac Oncol 12(2 Suppl):Abstract nr OA 17.06)

21. McDermott D, Lebbé C, Hodi FS, Maio M, Weber JS, Wolchok JD, Thompson JA, Balch CM (2014) Durable benefit and the potential for long-term survival with immunotherapy in advanced melanoma. Cancer Treat Rev 40:1056-1064. https:// doi.org/10.1016/j.ctrv.2014.06.012

22. Shukuya T, Mori K, Amann JM, Bertino EM, Otterson GA, Shields PG, Morita S, Carbone DP (2016) Relationship between overall survival and response or progression-free survival in advanced non-small cell lung cancer patients treated with antiPD-1/PD-L1 antibodies. J Thorac Oncol 11:1927-1939. https:// doi.org/10.1016/j.jtho.2016.07.017

23. Motzer RJ, Sharma P, Escudier BJ, McDermott DF, George S, Srinivas S, Tykodi SS, Sosman JA, Plimack ER, Nathan PD, Gruenwald V, Tomita Y, Zhao H, Waxman IM, Hammers HJ (2016) Correlation of response with overall survival (OS) for nivolumab vs everolimus in advanced renal cell carcinoma (aRCC): results from the phase III CheckMate 025 study. J Clin Oncol 34(15 Suppl). https://doi.org/10.1200/JCO.2016.34.15_ suppl.4552 (Abstract 4552)

24. Mushti SL, Mulkey F, Sridhara R (2018) Evaluation of overall response rate and progression-free survival as potential surrogate endpoints for overall survival in immunotherapy trials. Clin Cancer Res 24:2268-2275. https://doi.org/10.1158/1078-0432. CCR-17-1902

25. Eisenhauer EA, Therasse P, Bogaerts J, Schwartz LH, Sargent D, Ford R, Dancey J, Arbuck S, Gwyther S, Mooney M, Rubinstein L, Shankar L, Dodd L, Kaplan R, Lacombe D, Verweij J (2009) New response evaluation criteria in solid tumours: revised RECIST guideline (version 1.1). Eur J Cancer 45:228247. https://doi.org/10.1016/j.ejca.2008.10.026

26. Anderson JR, Cain KC, Gelber RD (1983) Analysis of survival by tumor response. J Clin Oncol 1:710-719

27. Dafni U (2011) Landmark analysis at the 25-year landmark point. Circ Cardiovasc Qual Outcomes 4:363-371. https://doi. org/10.1161/CIRCOUTCOMES.110.957951

28. Long GV, Weber JS, Infante JR, Kim KB, Daud A, Gonzalez R, Sosman JA, Hamid O, Schuchter L, Cebon J, Kefford RF, Lawrence D, Kudchadkar R, Burris HA III, Falchook GS, Algazi A, Lewis K, Puzanov I, Ibrahim N, Sun P, Cunningham E, Kline AS, Del Buono H, McDowell DO, Patel K, Flaherty KT (2016) Overall survival and durable responses in patients with BRAF V600-mutant metastatic melanoma receiving dabrafenib combined with trametinib. J Clin Oncol 34:871-878. https://doi. org/10.1200/jco.2015.62.9345

29. D’Angelo SP, Russell JS, Bhalla S, Hamid O, Mehnert JM, Terheyden P, Shih KC, Brownell I, Lebbé C, Lewis C, Linette GP, Milella M, Hennessy M, Zwiener I, Nghiem P (2018) 18-month efficacy and safety update from JAVELIN Merkel 200 part A: a registrational study of avelumab in metastatic Merkel cell carcinoma progressed on chemotherapy. J Clin Oncol 36(5 Suppl). 
https://doi.org/10.1200/JCO.2018.36.5_suppl.192 (Abstract 192)

30. Beer L, Hochmair M, Prosch H (2018) Pitfalls in the radiological response assessment of immunotherapy. Memo 11:138-143. https://doi.org/10.1007/s12254-018-0389-x

31. Calandri M, Solitro F, Angelino V, Moretti F, Veltri A (2018) The role of radiology in the evaluation of the immunotherapy efficacy. J Thorac Dis 10(Suppl 13):S1438-S1446. https://doi. org/10.21037/jtd.2018.05.130

32. Hoos A, Eggermont AM, Janetzki S, Hodi FS, Ibrahim R, Anderson A, Humphrey R, Blumenstein B, Old L, Wolchok J (2010) Improved endpoints for cancer immunotherapy trials. J Natl Cancer Inst 102:1388-1397. https://doi.org/10.1093/jnci/djq310

33. Wolchok JD, Hoos A, O'Day S, Weber JS, Hamid O, Lebbé C, Maio M, Binder M, Bohnsack O, Nichol G, Humphrey R, Hodi FS
(2009) Guidelines for the evaluation of immune therapy activity in solid tumors: immune-related response criteria. Clin Cancer Res 15:7412-7420. https://doi.org/10.1158/1078-0432.CCR-09-1624

34. Shapiro I, Grote HJ, D'Urso V, Von Heydebreck A, Mahnke L, Kaufman H, Nghiem P, Cai T (2017) Exploratory biomarker analysis in avelumab-treated patients with metastatic Merkel cell carcinoma progressed after chemotherapy. J Clin Oncol. https:// doi.org/10.1200/JCO.2017.35.15_suppl.9557 (Abstract 9557)

35. Buyse M, Molenberghs G (1998) Criteria for the validation of surrogate endpoints in randomized experiments. Biometrics 54:1014-1029

Publisher's Note Springer Nature remains neutral with regard to jurisdictional claims in published maps and institutional affiliations.

\section{Affiliations}

\section{Sandra P. D'Angelo ${ }^{1} \cdot$ Matthias Hunger $^{2} \cdot$ Andrew S. Brohl $^{3} \cdot$ Paul Nghiem $^{4} \cdot$ Shailender Bhatia $^{5} \cdot$ Omid Hamid $^{6}$. Janice M. Mehnert ${ }^{7} \cdot$ Patrick Terheyden $^{8} \cdot$ Kent C. Shih $^{9} \cdot$ Isaac Brownell ${ }^{10} \cdot$ Céleste Lebbé $^{11} \cdot$ Karl D. Lewis $^{12}$. Gerald P. Linette ${ }^{13} \cdot$ Michele Milella $^{14}$. Michael Schlichting ${ }^{15}$. Meliessa H. Hennessy ${ }^{16}$. Murtuza Bharmal ${ }^{15}$}

1 Memorial Sloan Kettering Cancer Center, Weill Cornell Medical College, 300 East 66th Street, 12th Floor, New York, NY 10065, USA

2 Mapi (An ICON plc Company), Munich, Germany

3 Moffitt Cancer Center, Tampa, FL, USA

4 Division of Dermatology, Department of Medicine, Seattle Cancer Care Alliance, University of Washington, Seattle, WA, USA

5 Division of Medical Oncology, Department of Medicine, Seattle Cancer Care Alliance, University of Washington, Seattle, WA, USA

6 The Angeles Clinic and Research Institute, Los Angeles, CA, USA

7 Rutgers Cancer Institute of New Jersey, New Brunswick, NJ, USA

8 University of Lübeck, Lübeck, Germany
9 Tennessee Oncology, Nashville, TN, USA

10 Center for Cancer Research, National Cancer Institute, Bethesda, MD, USA

11 Hôpital Saint-Louis, Paris, France

12 University of Colorado Cancer Center, Anschutz, Aurora, CO, USA

13 Hospital of the University of Pennsylvania, Philadelphia, PA, USA

14 IRCCS Regina Elena National Cancer Institute, Rome, Italy

15 Merck KGaA, Darmstadt, Germany

16 EMD Serono, Billerica, MA, USA 